\title{
Transitional Media: Duration, Recursion and the Paradigm of Conservation
} Hanna B. Hölling

University College London

Department of History of Art

Gower Street

London

WC1E $6 \mathrm{BT}$

United Kingdom

Correspondence to: Hanna Hölling, University College London, Department of History of Art, Gower Street, London, WC1E 6BT, United Kingdom

Email: h.holling@ucl.ac.uk

orcid.org/0000-0002-3063-4405

\begin{abstract}
[ABSTRACT]
Fostering conservation as a discursive and contextual practice, this essay examines transitional media that necessitate new ways of thinking about continuity. It looks at two examples of artworks with the objective of unravelling the varying modes of their transition. An event score, event-performance, object, and film drawn from the artistic legacies of George Brecht and Nam June Paik illustrate that ideas of permanence and impermanence are linked with an understanding of artworks in time and duration. While conservation reveals itself as an intervention in the temporal dimension of artworks, the theories of duration allow us to better understand the reciprocal relations between materials and meanings. In doing so, these theories acknowledge and attempt to make sense of the performative materiality of these works.
\end{abstract}

[KEYWORDS ]

Change; Conservation Theory; Continuity; Duration; Event; Time; Transition; Recursion

\section{Introduction}

'The essence of the medium is time.... Its basic underlying characteristics are change and transformation. ... The medium unfolds itself in time.'

Bill Viola

With these words American video artist Bill Viola convinces us that time, change, and transformation constitute the essential characteristics of a medium (Viola, 1999). Viola addresses artistic video, which, according to the German media theorist Dieter Daniels, bridges diverse genres (Daniels, 1992), including those of traditional art. The link between media is often established at the level of the artworks' intermediality and syntheses, which not only connects distinct art forms, but also appeals to multiple senses. Undoubtedly, Daniels' insight into these media entanglements is rooted in the tradition that grew from Dick Higgins' Intermedia (Higgins, 1966), John Cages' earlier activities on the crossroads of modernist music and visual arts, and the blending of art forms in the utopian project of the $19^{\text {th }}$ century Gesamtkunstwerk. Most importantly, however, the intermedia dynamics and musical origins of a large portion of the neo avant-garde art of the 1960s-70s including performance, installation art, and electronic media generated new, transitional types of artworks that induced an alternative way of thinking about their conservation (Hölling, 2013; 2015). Change, transformation and, no doubt, time, are intrinsic to all media.

\section{Conservation and intermediality}

Why, then, was the legacy of intermediality, electronic music (by Cage, or Karlheinz Stockhausen for example) and other forms of artistic activities such as events, happenings, and performances barely acknowledged in conservation and failed to be reflected in its theories? To be sure, the more recent conservation thinking that brought musical 
philosophies into play and drew conclusions about the iterant character of artworks significantly contributed to the shift in the traditional paradigm of conservation (Laurenson, 2006). This perception, together with the affirmation of change in artworks, offers fruitful ground for further scrutiny. What follows is an expansion of conservation's intellectual pursuit - an issue too often neglected under competing pressures to deal with the technical study of materials, direct manipulation of objects, and with the rhetoric of material authenticity. Here, the legacy of intermediality not only challenges the established categories in conservation and museum collecting and exhibiting practice, but also radicalizes time. Video, film, and multimedia incorporate and manipulate time; similarly, in short-duration artworks such as performance, (Fluxus) event, and process, time becomes an indicator of these works' identity.

Considerations of time and duration lift conservation to a level of discursivity that transcends its engagement with materials. I will say nothing new if I mention that many of the works created since the 1960 s evade the musealization, which occurs at the disjunction from their previous context and their afterlife as museum objects, and that subscribes to the values of material authenticity and to traditional conservation paradigm in preserving objects-things. Rather than rest incarcerated in a particular state or condition, these works transition fluidly from one state, or variant, to another and are better understood as a sum of their transformations - an effect of multiple agencies and a rhizome of origins,

developments, and stoppages. While change and changeability are indices of time, transition introduces yet another meaning of 'going beyond,' 'to the other side,' 'to cross over' (from Latin prefix: trans). For these artworks, change and transition are a condition of possibility for survival.

How does such a transition take place? And how can we make sense of the temporal existence of artworks to draw consequences for their continuity? Let us look at an example.

\section{Exit: object, event, time}

In a rather brightly lit gallery decorated with a number of artifacts, I cannot help but stare at a single sign affixed above the door. In red letters on a black background, and protected by a simple frame and glazing, we read 'Exit.' What does this mean? Is it art or a utilitarian artifact indicating the way out of the museum? Instantaneously, I think of the fire extinguisher that I spotted earlier in the museum and wrestle with the thought of their aesthetic similarity.

The sign in question is George Brecht's Exit (undated, Fig. 1, Collection Braun/Lief, Museum Ostwall Dortmund) created in the aftermath of his earlier work-an event score Exit from 1961 (Fig.2, extant in variants, such as FLUXUSVERSION I). Underappreciated for their impact on 1960s-70s conceptualism and on the increase of emphasis on the role of a spectator-participant, Brecht's events are also one of the most significant contributions to the development of intermedia and to sustaining their legacy after the 1960s. The events follow Brecht's idea that ' $\ldots$ the details of everyday life, the random constellations of objects that surround us, stop going unnoticed' (Johnson, 2008). They incorporate chance happenings and chance durations to achieve a multisensory 'total' experience (Brecht, 1970). Events rely on the concept of the score, which might be grasped as an instruction transposed into the medium of language (Osborne, 2002). Such conception of the event score implies the presence of interpreters that complicate authorial singularity and, tied to it, the paradigm of intentionality. This conception also asserts the freedom of interpretation and the presence of the artwork's multiple instances. Anyone can execute an event - as Exit shows here - and anyone should. With its short duration, the Fluxus event also stands for a generative amassment of objects in effect of its disappearance (Hölling, 2015, pp. 81-83)

From the diaries Brecht wrote on the occasion of his participation in Cage's classes at the New School for Social Research in New York 1958-59, one can deduce his deep intellectual investment in the concept of events and the conditions that enabled him to fulfill them. Events succinctly exemplify his interest in creating situations in which works are a means to an end and an end in themselves, simultaneously as documents, props, and leftovers. However, the back and forth between event and object is crucial when it comes to the artwork's temporal dimension, reconfirmed by him saying: 'Every object is an event and 
every event has an object-like quality, (s)o they're pretty much interchangeable' (Brecht in Dezeuze, 2005). Here, Brecht oscillates between a conceptual object and an object-based concept, challenging the dichotomy of permanence and impermanence.

How can we make sense of this for conservation? How can conservation attend to the temporal identity of this work and account for its materiality? Before attempting to answer this question, let us take another glimpse at the world of Exit.

\section{What, how, and where?}

The artwork, so far, has become an event score, a realized, or potentially realized, event and a sign, which manifest, nota bene, in multiple iterations. Additionally, the film Entrance to Exit (1965, figs. 3 and 4) may be counted within its universe. It presents 'a smooth linear transition from white, through greys to black, produced in developing tank', according to the description on the website of the Electronic Arts Intermix, New York (EAI, 2015). It continues: 'The 'door sign' ENTRANCE fades in, white letters on the black background, stays for a few seconds, then slowly fades into white. Five-minute fade into black and the title EXIT, which stays for a few seconds then fades into white'. In the absence of any narrative and filmic apparatus (camera, lens, film crew), and using silence, nothingness, and boredom as artistic means, the film is self-referential and presents the underlying characteristics of Fluxfilms (Ganz, 1988; Hölling 2015, pp. 4-10).

So what exactly is Exit? Is the work a work-thing or rather an event? Does the existence of Exit lie in all its singularities, which should be conserved as such, or do these singularities point to the multiplicity of its universe and the potentiality of its constant transition and change? What is the relation between its fractals and the whole? Where, how and what is the work? If, reverberating Brandian dictum, the imperative of conservation is, first of all, to understand what the work is; these questions must be faced, even if the final answers to them are far off. Here, conservation oriented towards the paradigms of material authenticity and point(s) of origins, including exclusively artistic, rather than other, intentions, quickly exhausts its capability to grasp, and to cope with, the intricacies and complexities of its 'object'. Matters of materials and display retreat to yield the fascinating questions of an ontological nature. These questions approximate the modes of the world and its making, even if, of necessity, the answers are always partial and conflicting (Goodman, 1978).

\section{Allochronic and autochronic}

Ontologically seen, the event score Exit presents us with a conundrum. First, Exit is an object-thing that exists as a card offering written instructions-'Word Event. Exit. G. Brecht Spring 1961.' Because the sign has a specific, fixed relation to time, it could be termed an autochronic work (the prefix 'auto' from Greek stands for 'self, one's own'). The quantitatively undetermined number of its interpretations would classify Exit as an allochronic work - a worked untethered to particular temporality (from Greek 'allos' meaning 'other', and opposite to 'auto'). I developed the argument of the temporal characteristics of artworks as an alternative to the dichotomy of the permanent and the impartment, and following Nelson Goodman's much-discussed distinction between forgeable (autographic) and unforgeable (allographic) arts (Hölling, 2015, pp. 83-5). Allochronic works, which usually last only for a short time, respond actively to time-they are repeatedly executed, 'updated,' and therefore, as a rule, more prone to extrinsic and intrinsic change. Autochronic works, in turn, respond to time passively-here change is linked with gradual decay and degradation (Hölling, 2013, 127-130). Allochronic and autochronic works are mutually related: autochronic works are often generated in the effect of the allochronic works' performance. Due to their long duration, autochronic works comply with the system of collectible objects and the traditional conservation's quest for permanence reflected in preserving artworks as objects-things.

It is interesting, at this point, to note that Brecht's artwork demonstrates certain similarities to Nam June Paik's Zen for Film (1962-64). Paik's iconic film, an empty film leader that runs through a projector and collects traces, has formal similarities to Entrance to Exit. Paik's film shares with Entrance to Exit both a tongue-in-cheek humor and also selfreferentiality. Because, in the vein of an allochronic work, the Zen for Film is repeatedly re- 
instantiated with the help of a new vintage projector and a new blank leader, the object-relic generated in the course of its existence, and now housed at the Gilbert and Lila Silverman Fluxus Collection at MoMA, assumes the characteristics of an autochronic object-thing. In that sense, Zen for Film shares with Exit the same temporal entanglement and interdependence between event and object.

\section{Vehicular and artistic medium}

Although I grapple extensively with this topic in my book Revisions (2015), for the purpose of this essay, I shall briefly mention one more aspect that Exit and Zen for Film share: the complex relation between the artistic and vehicular medium. Proposed by the analytic philosopher David Davies (Davies, 2004, pp.58-59), the 'physical' or 'vehicular' (paint and canvas, body) medium distinguishes itself from the 'artistic' medium (brush strokes, articulated steps). Artistic statement is articulated through artistic medium in part and through the manipulation of the vehicular medium. Artistic medium mediates between what the artist does and what the work says. Of course, it would be a simplification to say that all physical carriers of an artistic statement are equivalent to the vehicular medium. But I suggest that the artistic media of Exit and Zen for Film are fully reflected in their performative qualities while the object-relics and left-overs-the sign in the case of Exit, or the filmic remnant in Zen for Film - are manifestations of the vehicular, physical, and autochronic medium. From yet another perspective, it might be said that the 'unruliness' of these works (Dominguez Rubio, 2014) exhibits itself in multiple vehicular media that embody artistic medium.

In traditional conservation, significant weight is put on vehicular medium, understood as an equivalent of artistic statement and valued for the history of its origins. This emphasis seems to wrongly relegate artistic media to physical carriers, often linked with the notion of intentionality. The latter is a matter of contention, to only consider, for instance, the concept of high and low-level intentionality (Dippert, 1988, pp. 182-200; Hölling, 2013, pp. 69-70), not resolvable here for reasons of space.

\section{Recursion}

Now, putting the aspect of the vehicular medium aside for a moment, what to the same extent connects these artworks is an idea of recursion and the relation between reproduction and repetition. Imagine, using an example taken from everyday life, placing two mirrors parallel to each other: the image, then, acquires a nested character that occurs in the form of seemingly infinite recursion. Deriving from linguistics, cybernetics, computer science, and visual arts, recursion is a complex concept that allows generating both simple and highly complex, multi-hierarchic structures (Martins \& Fitsch, 2014; Corballis, 2011). There are multiple definitions of recursion in different fields, but it might generally be said that recursion demonstrates how units of meaning in symbolic forms, including language, are combined and embedded (Irvine, 2015). Recursive embedding in language, for instance, is manifested in quotations, citations, and references.

Although both iteration and recursion involve repetition, iteration explicitly uses a repetition structure. Unlike iteration, which, proximate to reproduction, designates the process of repeating an action or object an arbitrary number of times, with each repetition being a separate act that can exist apart from the others, recursion involves embedding the action or object within another instance of itself and may involve hierarchic orders.

Although recursion demonstrates certain similarities to reproduction, it does not aspire to reproduce something in the sense of ceaselessly repeating its structure in an unrelated set of events. Brecht's Exit, when analyzed in terms of recursion, would embed ever new forms of Exits within the initial concept formulated by the event score, and rather than displacing the old work, subsequent manifestations would carry its essence in their conceptual or formal structures.

Here, intermediality comes back into the picture, not as a fusion of art forms, but as the intermediality's varying forms - as transposition in the sense of adapting one medium to the requirements of another medium, as re-presentation, and as remediation (Lushetich, 2012). The wandering of Exit from an instruction-score to event, to performance, to film, and to object(s) is a succinct example of such intermediality. 
I also suggest that recursion perhaps most closely represents the idea of an artistic medium that is invariably being embodied in variants - mirror images, quotations, and references. As such, recursive structures of an artwork would embrace both its allochronic and autochronic variants.

To grasp recursion and intermediality means also to grapple with plural temporalities. It is first the artwork at the beginning of the mirror image and its temporal embedding within the technological status of that time. It is then the recursive structure in the process of constant formation that introduces new vehicular media carrying the artistic statement and characterized by their intrinsic temporalities. Last but not least, it is the selfreferentiality of the artwork in the recursive structure that never finds itself outside of this reference circle and where the new is never truly new because, by creating an impression of novelty, it repeats and restages reality. Here, continuity of form, rather than material, is secured by constant renewal. 'Worldmaking as we know it always starts with worlds already on hand; the making is remaking' (Goodman, 1978, p. 6).

\section{Conclusions: conservation as temporal intervention}

Regarding the idea of recursion with all the seriousness it deserves, a question must be posed as to whether the notion of conservation can be sustained. Clearly, the paradigm of conservation related to the rhetoric of authenticity and culture of material sustainability reached its limits confronting the worlds of transitional media and their 'going beyond' and 'crossing over' to new, unfamiliar territories. Perhaps, a possible scenario would be to rethink the notion of conservation as an intervention in the temporal dimension of artworks. Arguably, what conservation does is introduce stoppages, interruptions, and attempts of the reversion of time (conveyed in traditional approaches and the word 'restoration' which implies very specific ideas about time, chronology, and reversibility) (Hölling, 2013, pp. 14970). The quest for permanence is a fallacy because everything is constantly moving along a trajectory defined by the relative duration of the impermanent (Brisley, 2008). The unfolding of the medium in time suggested by Viola at the beginning of this essay may imply, in long duration, a recursive unfolding. An ultimate recourse from the traditional categorization of media to which intermedia already became an antidote could possibly be sought in the observation of their transition. In other words, the medium is that which transitions and changes, and, consequently, it is characterized by the specificity of its change. Finally, and if nothing else, through transitional media, we may learn how to incorporate the acceptance of changeability into the paradigm of conservation and understand our discipline as a necessarily discursive and contextual practice.

\section{[ACKNOWLEDGEMENTS]}

Parts of this article were developed during my tenure as Andrew W. Mellon Visiting Professor at the Bard Graduate Center in New York, at the Max Planck Institute for the History of Science in Berlin, and the Department of History of Art at University College London. I would like to express my gratitude to the foundation and to my faculty colleagues and friends who supported me.

\section{[REFERENCES]}

Brecht, G. 1970. The Origin of 'Events.' In: H. Sohm \& H. Szeeman, eds. Happening und

Fluxus: Materialien. Cologne: Kölnischer Kunstverein, 1970.

Brisley, S. 2008. 'The Photographer and the Performer.' In: A. Maude, ed. Live Art on Camera . Southampton: John Hansard Gallery, pp. 83-88.

Corballis, M. C. 2011. The Recursive Mind: The Origins of Human Language, Thought, and Civilization. Princeton: Princeton University Press.

Daniels, D. 1992. The Birth of Electronic Art out of the Spirit of Music. In: K. Friedman, ed.

Fluxus Virus. Cologne: Galerie Schüppenhauer, pp. 159-162.

Davies, D. 2004. Art as Performance. Oxford: Blackwell.

Dezeuze, A. 2005. Brecht for Beginners. Papers of Surrealism, 4: 1-11.

Dipert, R. R. 1988. Towards a Genuine Philosophy of the Performing Arts. Reason Papers, 13: $182-200$. 
Dominguez Rubio, F. 2014. Preserving the Unpreservable: Docile and Unruly Objects at MoMA. Theory and Society, 43(6): 617-645. Available at:

$<$ http://escholarship.org/uc/item/9qr4d9qx>

EAI Electronic Arts Intermix. 2015. 'George Brecht: Entrance to Exit, 1965.' [accessed 28

December 2015]. Available at: <http://www.eai.org/title.htm?id=14177>.

Ganz, J. 1988. 'An Introduction to the Fluxfilm: Notes on Films in the Gilbert and Lila Silverman Collection.' Master's thesis, Williams College Graduate Program in the History of Art.

Goodman, N. 1978. Ways of Worldmaking. Indiana: Hackett Publishing.

Higgins. D. 1966. Statement on Intermedia. In: W. Vostell ed. Dé-coll/age (décollage). Frankfurt and New York: Typos Verlag \& Something Else Press, No. 6.

Hölling, H. 2013. Re:Paik-On Time, Changeability and Identity in the Conservation of Multimedia installations. Ph.D Thesis, University of Amsterdam. 's-Hertogenbosch: Uitgeverij BOXPress.

Hölling, H. 2015. Revisions_Zen for Film. New York and Chicago: Bard Graduate Center and Chicago University Press.

Irvine, M. 2015. Remix and the Dialogic Engine of Culture: A Model for Generative Combinatoriality. In: E. Navas \& O. Gallangher, eds. The Routledge Companion to Remix Studies. New York: Routledge, pp. 15-42.

Johnson, K. 2008. George Brecht: Obituary. New York Times (15 December 2008) [accessed 10 December 2015]. Available at: <http://www.nytimes.com/ 2008/12/15/arts/music/15brecht.html?_r=0>.

Laurenson, P. 2006. 'Authenticity, Change and Loss in the Conservation of Time-Based Media Installations.' Tate Papers, 6. [accessed 12 December 2014]. Available at: < http://www.tate.org.uk/download/file/fid/7401>.

Lushetich, N. 2012. Fluxus: The Practice of Non-Duality. Amsterdam and New York: Rodopi.

Martins, M.D. \& Fitch, W.T. 2014. Investigating Recursion Within a Domain-Specific Framework. In: F. Lowenthal \& L. Lefebvre, eds. Language and Recursion. New York: Springer, pp. 15-26.

Osborne, P. 2002. Conceptual Art: Themes and Movements. London: Phaidon.

Viola, B. 1999. Permanent Impermanence. In: M.A. Corzo, ed. Mortality, Immortality?: The Legacy of 20th-Century Art. Los Angeles: Getty Conservation Institute, pp. 85-94.

\section{[SUGGESTED QUOTATION]}

Hanna B. Hölling. "Transitional Media: Duration, Recursion and the Paradigm of Conservation." Saving the Now, preprints of the International Committee of Conservation (IIC) 2016 Los Angeles Congress, in collaboration with the International Network for the Conservation of Contemporary Art (INCCA). Special issue of Studies in Conservation, Vol. 61 (2016):79-83. 


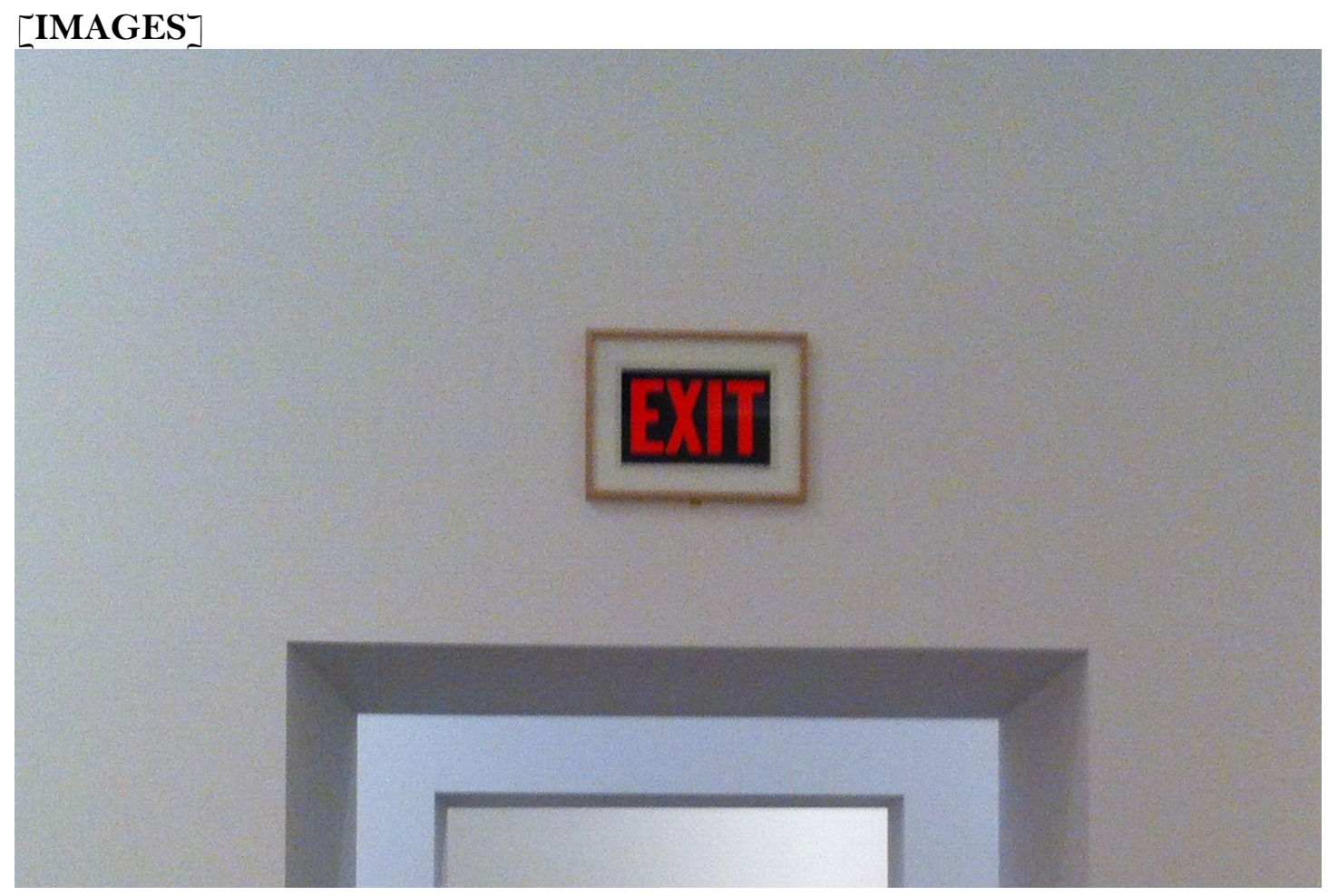

Figure 1 George Brecht, Exit (Word Event), no date (after 1961), removable plastic foil on cardboard. Courtesy Museum am Ostwall, Dortmund, Germany (C) VG-Bild-Kunst, Bonn 2016 Photo C Hanna Hölling

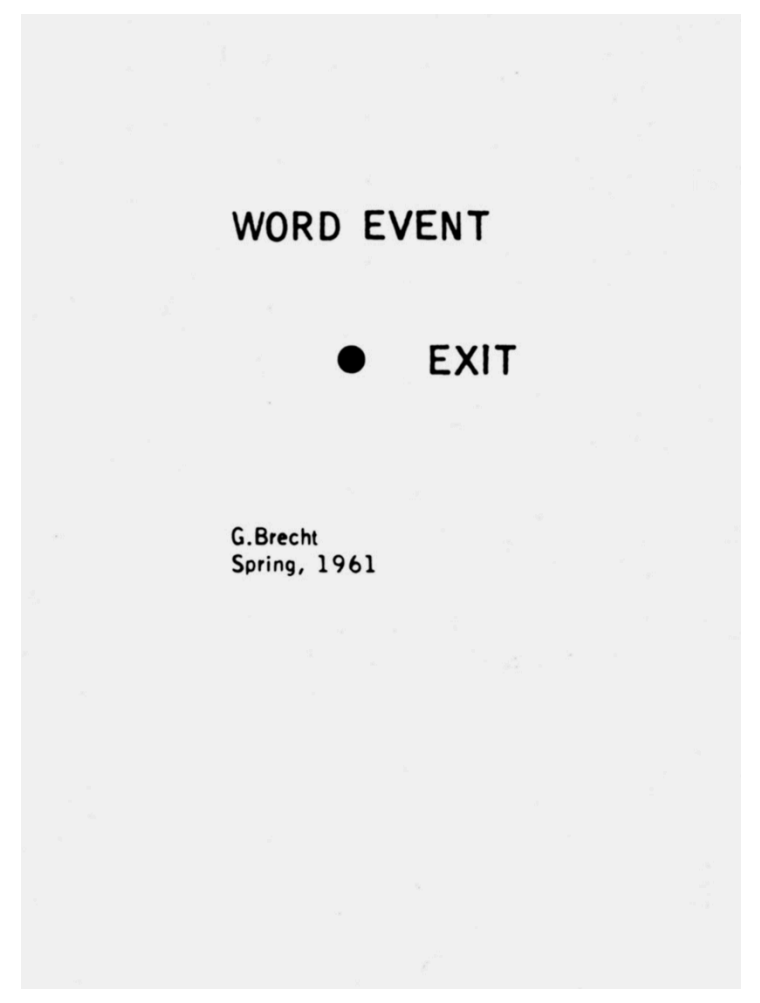

Figure 2 George Brecht, Exit, 1961, word eventevent score. Private collection (C) VG-Bild-Kunst, Bonn 2016 


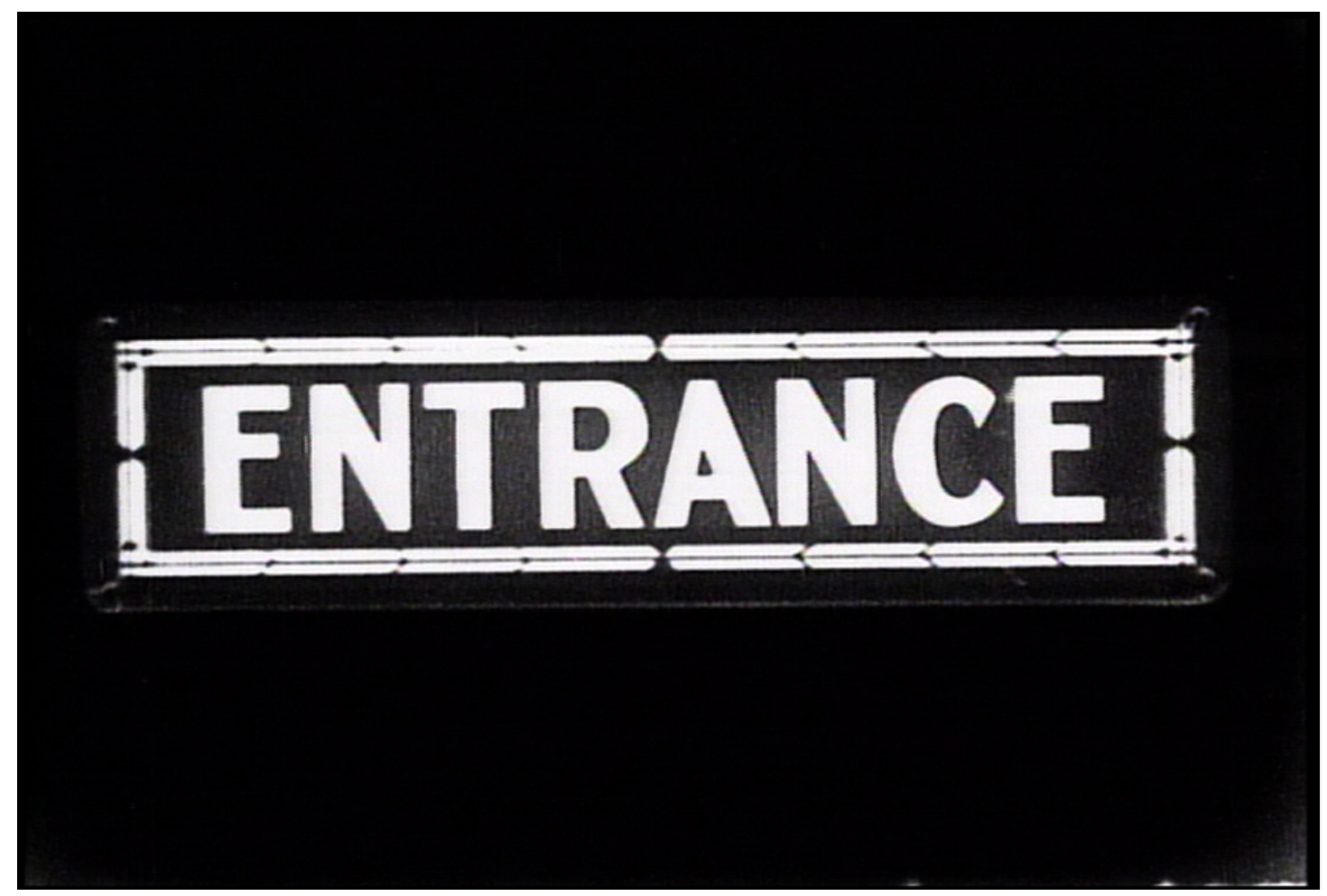

Figure 3 Film still from: George Brecht, Entrance to Exit (Fluxfilm no. 10), 1965, 7 minutes, black and white, sound. Courtesy Electronic Arts Intermix (EAI), New York and Anthology Film Archives (C) VG-Bild-Kunst, Bonn 2016

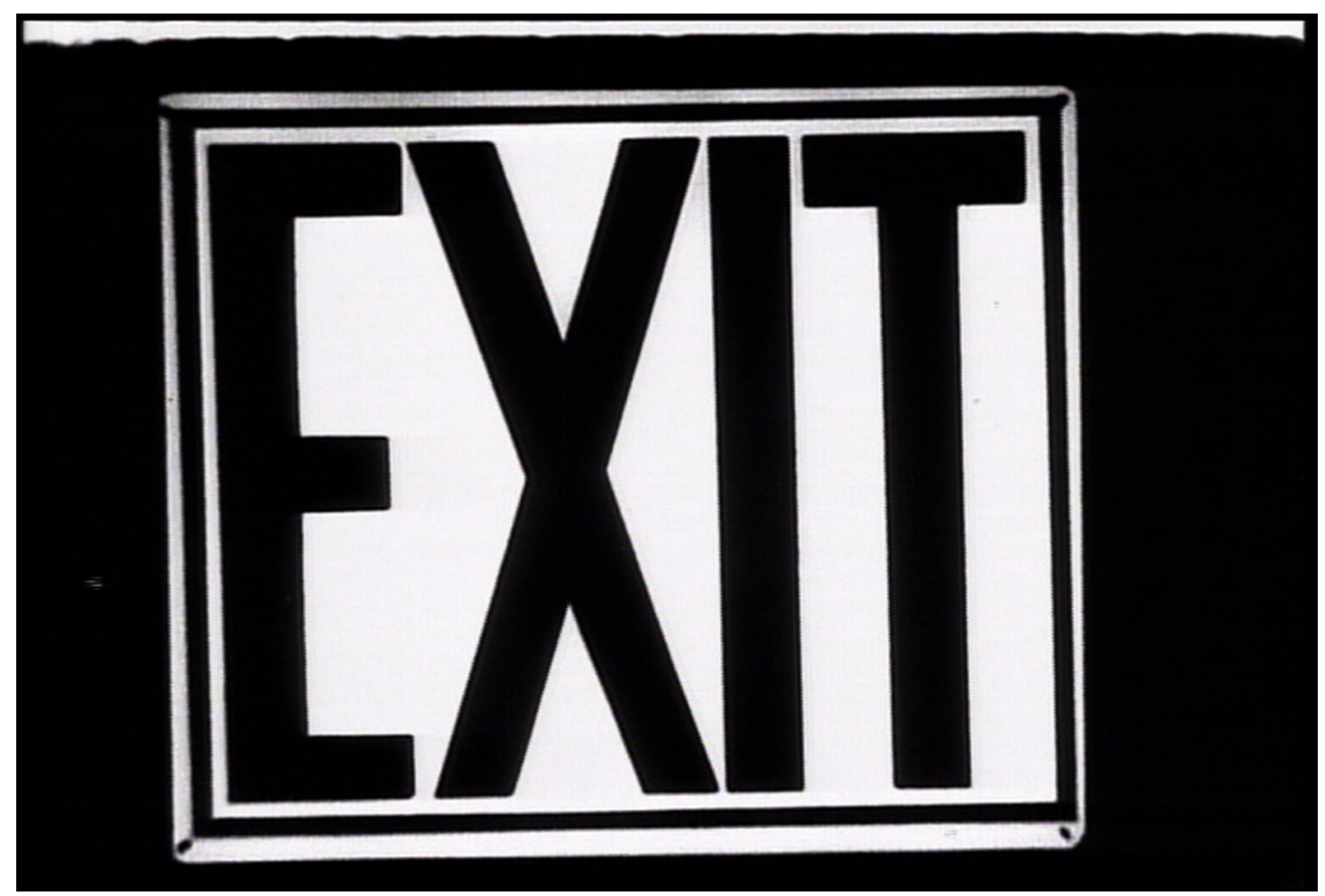

Figure 4 Film still from: George Brecht, Entrance to Exit, (Fluxfilm no. 10), 1965, 7 minutes, black and white, sound. Courtesy Electronic Arts Intermix (EAI), New York and Anthology Film Archives (C) VG-Bild-Kunst, Bonn 2016 